\title{
Empirical Yield-effort Models for Bangladesh Inland Fisheries
}

\author{
Ashley Stewart Halls ${ }^{1}$ and Md. Golam Mustafa ${ }^{2^{\star}}$ \\ ${ }^{1}$ Aquae Sulis Ltd, Midway House, Bath, BA15 2LR, UK. \\ ${ }^{2}$ WorldFish, Bangladesh Office, House 22B, Road 7, Block F, Banani, Dhaka, 1213, Bangladesh.
}

Authors' contributions

This work was carried out in collaboration between both authors. Both authors read and approved the final manuscript.

Article Information

DOI: $10.9734 / \mathrm{JALSI} / 2017 / 33858$

Editor(s):

(1) Dr. Palanisamy Arulselvan, Institute of Bioscience, Universiti Putra Malaysia, Malaysia.

Reviewers:

(1) Tiogué Tekounegning Claudine, The university of Dschang, Cameroon.

(2) Akeem Babatunde Dauda, Federal University Dutsinma, Nigeria. Complete Peer review History: http://www.sciencedomain.org/review-history/19594

Original Research Article

Received $1^{\text {st }}$ May 2017 Accepted $29^{\text {th }}$ May 2017 Published $17^{\text {th }}$ June 2017

\section{ABSTRACT}

Aims: To support community-based fisheries management (CBFM) of inland fisheries resources in Bangladesh.

Study Design: An investigation into the impact of the nationwide CBFM Project and four alternative yield-effort models were fitted to the catch (yield) and effort data.

Place and Duration of Study: The study comprised community managed fisheries (sites) located in five different inland water habitat types in Bangladesh for the period 1997-2005.

Methodology: Using data compiled for this impact assessment, the aggregated yield-effort response is examined in more detail among different habitats as a means of providing local managers with guidance on controlling fishing effort.

Results: An effort-based analogue of the ad hoc ' $F_{0.1}$ strategy' $E_{0 . x}$ is proposed as a management reference point to be used with this model. Estimates of fishing effort at $x=1$ and 2 and corresponding yield $\left(Y_{E_{0 . x}}\right)$ and catch rates $\left(C P U E_{E_{0 . x}}\right)$ are also provided for the five habitats examined. Values for $x$ of between 1 and 2 give rise to a CPUE of approximately $40-50 \%$ of the predicted maximum CPUE. Catch rates may be used to monitor progress towards the selected reference point. As a general 'rule of thumb' for the fisheries examined, catch per fisher, averaged over the year, corresponding to the reference point is approximately $0.5 \mathrm{~kg} \mathrm{~d}^{-1}$ when $x=1$ and 0.7 
$\mathrm{kg} \mathrm{d}^{-1}$ when $x=2$. The asymptotic model provided the best description of the yield-effort response for floodplain and Haor beel habitats and the sigmoid model provided best description of the data for the Open beel and River habitats. The Schaefer model provided the best description of the data for closed beel habitat. However, among all habitats the Fox model was the least favoured model.

Conclusion: Both the asymptotic and the sigmoid model each provided the best description of the yield-effort response within two habitats. The Schaefer model provided the best description of the data for closed beel habitat. The study has provided evidence that across habitat favoured an asymptotic yield-effort model (Akaike weight 0.85 ) as being the most generally applicable.

Keywords: Community-based management; multispecies yield-effort models; fishing effort, Inland fisheries.

\section{INTRODUCTION}

Small-scale fisheries resources are lifeline to the 18.2 million people in subsistence fisher communities in Bangladesh [1]. Fisheries sector contributed $3.65 \%$ to national GDP, $23.81 \%$ to the agricultural GDP in 2014-15 [1]. The floodplain-river fisheries of Bangladesh support the livelihoods of millions of poor people but landings and species diversity are believed to be declining as a result of high rates of exploitation and habitat degradation. The significant decline in fish production over the last 20 years can also be attributed to the current access right system and absence of proper conservation measures, which have largely contributed to overfishing, deforestation of swamp forest and restricted migration of fish during spawning season [2]. Waterbody leasing policy had changed over time. Than main fisheries policy changed in 1995 by declaring "free access to open waterbodies" in order to remove difficulties faced by fisher groups. This declaration made open water fisheries management more difficult, as local muscle men took advantage of the open access by excluding poor people from the resources thus, unlimited access for fishing was established [3]. Besides, lack of awareness by the resource user, manpower by the law enforcing agencies, inter-organizational conflict etc. are the major concern averting the law in enforce [4].

The Community Based Fisheries Management (CBFM) Project, funded by the Ford Foundation and the UK Government's Department for International Development (DfID), began in 1996 and aimed to promote the sustainable use of, and equitable distribution of benefits from, inland fisheries resources by empowering communities to manage their own resources [5]. By 2005 the Project had facilitated the establishment of 120 community-based organizations (CBOs) located in regions throughout Bangladesh representing more than 23,000 poor fishing households [5].
Each CBO was responsible for the management of a defined area of fish habitat which included depressions or beels on the floodplain that form perennial or seasonal lakes, as well as sections of river channel [5]. The CBOs were encouraged to implement a variety of management interventions including, closed seasons, gear bans, harvest reserves (sanctuaries) and stocking waterbodies with fingerlings.

The control of fishing mortality via fishing effort is typically a fundamental element of most fisheries management strategies. Whilst fishing effort was controlled spatially (with reserves) and intraannually (with closed seasons) at some CBFM project sites, no apparent attempts were made to manage overall levels of effort during any given year. These overall levels of effort were instead largely governed by the numbers of fishers initially and subsequently granted access to the resource determined on the basis of their socioeconomic and historic-dependence upon the resource. Effort among sites was therefore dictated more by the prevailing local demographic and socio-economic than resource considerations.

This probably reflects the priorities of the Project but also a lack of knowledge of the response of aggregated yield (catch) and fish abundance to changes in fishing effort across the range of exploited habitats. Even imprecise knowledge of the response is likely to be of benefit, particularly under adaptive management strategies [6]. Similar study has provided evidence that community-based resource management approached aimed at river tributaries improve fisheries production and biodiversity while also reducing the threat of climate change impacts on the poor people [2].

An investigation into the impact of the CBFM Project on key indicators of management performance unsurprisingly reported the strong 
dependence of aggregated fish yield and abundance on fishing effort [7]. Using data compiled for this impact assessment, we further investigate this response as a means of providing local managers with guidance on controlling fishing effort.

The most rudimentary approach to elucidating the relationship between yield and effort in multispecies fisheries is to ignore any species interactions and fit some form of production model to annual yield and effort estimates aggregated across all species [8]. Fitting such aggregated yield-effort models assumes that any species interaction effects and changes in catchability are captured in an overall relationship between catch and effort.

When little or no data are available for a single fishery, combining estimates of catch and effort across fisheries or locations can provide an indication of the likely response and be described by an empirical aggregated yield-effort model [9]. Models of this type can provide guidance to managers regarding potential yield and corresponding fishing effort as well as the expected response of fish abundance (indicated by CPUE) to effort. This comparative approach assumes that observations from discrete fisheries or sites (spatial and temporal replicates) can be treated as samples from a hypothetical fishery. Assuming the fishery covers the entire area, differences in scale are accounted for by standardizing both yield (catches) and effort by the surface area of the body of water. The approach does, however, assume that the observed catches are sustainable at the observed levels of effort, i.e. the stock is at equilibrium and therefore model predictions should be treated with caution. Published examples of empirical aggregated yield-effort models and also provide a detailed account of the historical and theoretical foundations of the approach and present empirical evidence for a general sigmoid form of the yield-effort response $[6,10]$.

\section{MATERIALS AND METHODS}

\subsection{Data}

The dataset comprised 366 estimates of annual aggregated yield and corresponding fishing effort for 105 community managed fisheries (sites) located in five different habitat types for the period 1997-2005. On average, yield and effort estimates were available for between two and four years in each habitat (Table 1). Most (approximately 90\%) corresponded to the same period (2002-2005). Beel habitat was categorised according to hydrological and morphological characteristics hypothesised to affect yield (Table 2).

The estimates of annual aggregated yield and effort were generated using a catch assessment survey undertaken bi-monthly at each site. Species-wise catch by gear type during each bi-monthly two-day sampling period was estimated as the product of the mean catch rate $\left(\mathrm{kg} \mathrm{h}^{-1}\right)$ for each gear type gear $g$, the mean number of fishers operating gear type $g$, the mean hours per day spent fishing with gear $g$ and the number of days in the sampling period (15 days). The bi-monthly estimates were then summed to provide monthly and annual estimates. Sites for which catch and effort estimates were not available in every month for a given year were excluded from the analysis. Between 1997 and 2005, the survey recorded more than 90 species of fish landed by 11 categories of gear.

Table 1. Characteristics of the four types of beel habitat

\begin{tabular}{|c|c|c|}
\hline \multirow[t]{2}{*}{ Habitat } & \multicolumn{2}{|c|}{ Characteristics } \\
\hline & Hydrological & Morphological \\
\hline Closed beel & $\begin{array}{l}\text { Perennial waterbody; little connectivity } \\
\text { to the main channel. }\end{array}$ & $\begin{array}{l}\text { Located on floodplains and generally } \\
\text { small in size. }\end{array}$ \\
\hline Floodplain beel & $\begin{array}{l}\text { Seasonally inundated by rainfall and } \\
\text { overspill from adjacent rivers. }\end{array}$ & $\begin{array}{l}\text { Shallow depressions in low-lying } \\
\text { areas of floodplain, typically paddy } \\
\text { land. }\end{array}$ \\
\hline Haor beel & $\begin{array}{l}\text { Large areas are perennial. Hydrology } \\
\text { determined mainly by river overspill. }\end{array}$ & $\begin{array}{l}\text { Extensive shallow basin located } \\
\text { between natural levees of rivers. } \\
\text { Often reduced to a series of isolated } \\
\text { beels during the dry season. }\end{array}$ \\
\hline Open beel & $\begin{array}{l}\text { Perennial waterbodies with many } \\
\text { connections to the main river channels. }\end{array}$ & $\begin{array}{l}\text { Located on floodplains and generally } \\
\text { small in size. }\end{array}$ \\
\hline
\end{tabular}


Table 2. Summary of the data sets used

\begin{tabular}{lllll}
\hline Habitat & $\begin{array}{l}\text { Number of paired } \\
\text { estimates of yield and } \\
\text { effort }\end{array}$ & $\begin{array}{l}\text { Number of } \\
\text { individual sites }\end{array}$ & $\begin{array}{l}\text { Mean number of } \\
\text { paired estimates } \\
\text { per site }\end{array}$ & Period \\
\hline $\begin{array}{l}\text { Closed beel } \\
\text { (CB) }\end{array}$ & 27 & 13 & 2.1 & $2000-2005$ \\
$\begin{array}{l}\text { Floodplain beel } \\
\text { (FPB) }\end{array}$ & 107 & 28 & 3.8 & $1999-2005$ \\
Haor beel (HB) & 40 & & & \\
Open beel (OB) & 76 & 10 & 4.0 & $2002-2005$ \\
River (R) & 116 & 28 & 2.7 & $1997-2005$ \\
Total & 366 & 26 & 4.5 & $1997-2005$ \\
\hline
\end{tabular}

When dealing with a multi-gear fishery, it is desirable to estimate the combined effort for all gear types in operation. To account for differences in their catchability $(q)$ this may be achieved by expressing effort relative to a standard gear type. Whilst this is straightforward for fisheries operating few gear types in relatively non-seasonal environments, the exercise is notoriously difficult to achieve satisfactorily for floodplain-river fisheries. This is because both gear use and gear catchability is highly seasonal in response to variation in hydrological conditions during the year. Missing effort observations for gear-season combinations often necessitates dropping gears from the dataset and/or reducing the number of fishing seasons over which catchability is relatively constant. The net effect is often standardised effort which bears little relationship to fishing mortality [11].

For this reason, fishing effort was expressed simply as number of fishers without regard to the type of gear employed. This is a common approach for analyses of this type [6]. Furthermore, to account for differences in scale among the sites, the estimates of aggregated annual yield and effort were expressed on a per unit area basis.

\subsection{Fitted Models}

Four alternative yield-effort models were fitted to the catch (yield) and effort data: the Schaefer [12] and Fox [13] models (Eq. 1 and 2, respectively), an asymptotic model described by [14] (Eq. 3) and a sigmoid model described by [10] (Eq. 4):

$$
\begin{aligned}
& Y=\left(a E+b E^{2}\right) \exp (\varepsilon) \\
& Y=[E \exp (a+b E)] \exp (\varepsilon) \\
& Y=\{a[1-\exp (b E)]\} \exp (\varepsilon)
\end{aligned}
$$

$$
Y=\left[\frac{c}{1+\exp [a(b-E)]}\right] \exp (\varepsilon)
$$

Where $Y$ is annual multispecies (aggregated) yield, $E$ is the annual fishing effort, $a, b$ and $c$ (or $\left.Y_{\max }\right)$ are the fitted parameters, and $\varepsilon$ is a $\log$ normally distributed random error.

Following the approach employed by [10], the parameters of each model were estimated using the maximum likelihood method to provide estimates of maximum yield $(M Y)$, and for the Schaefer and Fox models, corresponding fishing effort $E_{M Y}$. The minimum negative log likelihood $L L$ for model $m$ is given by [15]:

$$
L L_{m}=\frac{n}{2}[\operatorname{Ln}(2 \pi)+2 \operatorname{Ln}(\hat{\sigma})+1]
$$

Where

$$
\hat{\sigma}^{2}=\sum_{i=1}^{n} \frac{\left(\operatorname{Ln}\left(Y_{i}\right)-\operatorname{Ln}\left(\hat{Y}_{i}\right)\right)^{2}}{n},
$$

and $n$ is the number of observations, $Y_{i}$ is the observed yield for replicate $i$, and $\hat{Y}_{i}$ is the predicted yield for effort $E_{i}$ given the maximum likelihood parameter estimates for model $m$.

The best model $m$ for each habitat was identified as that which had the lowest Akaike information criterion (AIC) [15]:

$$
A I C_{m}=2 L L_{m}+2 p
$$

Where $p$ is the number of model parameters estimated.

Approximate $95 \%$ confidence intervals for the parameters $(\theta)$ of the best model were estimated as those corresponding to the following negative log likelihood [15]: 


$$
L L_{m}(\theta)=L L_{m}(\theta)_{\min }+\frac{\chi^{2} v, 1-\alpha}{2}
$$

Where $L L_{m}(\theta)$ is the negative log likelihood for the parameters $\theta, L L_{m}(\theta)_{\min }$ is the minimum negative log likelihood for the parameters $\theta, v$ is the degrees of freedom (having a value of 2 for model (1)-(3) and or 3 for model (4)) and $\alpha=0.95$.

The best model among all habitats (overall) was identified as the one which had the lowest AIC after first summing (combining) the negative log likelihoods for each habitat, $h$ :

$$
A I C_{m, \text { combined }}=2 p+2 \sum_{h} L L_{m, h}
$$

The probability that model $m$ is the best among the $k$ candidate models was estimated using Akaike weights $w_{m}$ :

$$
W_{m}=\frac{\exp \left(-\Delta_{m} / 2\right)}{\sum_{k=1}^{4} \exp \left(-\Delta_{k} / 2\right)}
$$

Where

$$
\Delta_{m}=A I C_{m, \text { combined }}-\min A I C_{\text {combined }}
$$

\section{RESULTS}

The Akaike information criterion (AIC) indicated that for closed beel habitat, the Schaefer model (Eq. 1) provided the best description of the yield-effort response predicting a maximum yield (MY) of approximately $500 \mathrm{~kg} \mathrm{ha}^{-1}$ year ${ }^{-1}$ at approximately $850 \mathrm{~d} \mathrm{ha}^{-1}$ year ${ }^{-1}$. (Fig. 1 , Table 3). Confidence intervals around the estimates of maximum yield (MY) and corresponding effort $\left(E_{M Y}\right)$ could not be determined from the likelihood profile because the boundaries of the approximate lower $95 \%$ confidence intervals lay outside minimum possible values for the model parameters $a$ and $b$. According to the Schaefer model, fisher communities appear to have fully exploited this habitat at some sites, but overall there is little evidence to suggest that yield could be improved through effort reductions.

The yield-effort response in both haor and floodplain bee/ habitat was best described by the asymptotic model (Eq. 3). The model predicted a maximum yield of approximately $400 \mathrm{~kg}$ ha year $^{-1}$ in both habitats with $95 \%$ confidence intervals ranging from approximately $260-700 \mathrm{~kg}$ ha $^{-1}$ year $^{-1}$ (Fig. 1, Table 3).

The Akaike information criterion (AIC) favoured the sigmoid model in the remaining open beel and river habitats with predicted maximum yields of approximately $770 \mathrm{~kg} \mathrm{ha}^{-1}$ year $^{-1}(95 \% \mathrm{Cl}$ $[480,1306])$ and $690 \mathrm{~kg} \mathrm{ha}^{-1}$ year $^{-1}(95 \% \mathrm{Cl}$ [454, 854]) respectively (Fig. 1 and Table 3).

Among all habitats, the Akaike weight favoured the asymptotic model with an $85 \%$ chance of being the best among the four considered here (Table 4).

\section{DISCUSSION}

Based upon among fishery comparisons [6] found that the Fox model, fitted using non-linear least squares assuming a normal residual error structure, best described the response of multispecies (aggregated) yield to effort for a number of different habitat types although the comparison did not include the sigmoid model. A more thorough investigation by [10], which included a subset of the same data, offers a compelling argument in favour of the sigmoid model as being the most generally applicable description of this response across a range of different systems.

Here, both the asymptotic (Eq. 3) and the sigmoid model (Eq. 4) each provided the best description of the yield-effort response within two habitats. The Schaefer model provided the best description of the data for closed beel habitat. However, among all habitats, the Akaike weight favoured the asymptotic over the sigmoid model while the Schaefer was the least favoured model. These results appear not to lend support for the apparent generality of the sigmoid model, at least for floodplain-river habitat in Bangladesh for which the asymptotic model appears more generally applicable.

The results presented here predict that aggregated yield from closed beel habitat in Bangladesh will decline with increasing effort. Fisher communities appear to have fully exploited this habitat at some sites, but overall there is little evidence to suggest that yield could be improved through effort reductions. In the remaining habitat, yield has been, and is predicted to be, sustained even at very high levels of effort. Indeed, this response may become evident in closed beel habitat as further observations of yield at higher levels of effort become available. 
Table 3. Model parameter estimates with $95 \%$ confidence intervals $(\mathrm{CI})$ and AIC

\begin{tabular}{|c|c|c|c|c|c|c|c|c|c|c|c|}
\hline \multirow[t]{2}{*}{ Habitat } & \multirow[t]{2}{*}{ Model } & \multirow[t]{2}{*}{$n$} & \multirow[t]{2}{*}{ AIC } & \multirow[t]{2}{*}{ Rank } & \multicolumn{3}{|c|}{ Parameter estimates } & \multirow[t]{2}{*}{ MY } & $\begin{array}{l}\text { MY } \\
\text { (upper }\end{array}$ & $\begin{array}{l}\text { MY } \\
\text { (lower) }\end{array}$ & \multirow{2}{*}{$\begin{array}{l}E_{M Y} \\
\text { d ha }^{-1} \text { year }^{-1}\end{array}$} \\
\hline & & & & & $a$ & $\boldsymbol{b}$ & $c$ & & \multicolumn{2}{|c|}{$\left(\mathrm{kg} \mathrm{ha}^{-1}\right.$ year $\left.^{-1}\right)$} & \\
\hline \multirow[t]{4}{*}{ Closed beel } & Schaefer & 27 & 56.98 & 1 & 1.1844 & 0.00069 & - & 507 & NE & NE & 856 \\
\hline & Fox & 27 & 57.32 & 2 & 0.15286 & -0.00064 & - & 669 & & & 1561 \\
\hline & Asymptotic & 27 & 57.42 & 3 & 884.6 & 0.00131 & - & 885 & & & \\
\hline & Sigmoid & 27 & 59.47 & 4 & 0.01003 & 253.8 & 518 & 518 & & & \\
\hline \multirow[t]{4}{*}{ FPB } & Schaefer & 107 & 257.33 & 4 & 0.7072 & 0.00015 & - & 815 & & & 2305 \\
\hline & Fox & 107 & 244.55 & 2 & -0.180 & -0.00060 & - & 512 & & & 1667 \\
\hline & Asymptotic & 107 & 237.73 & 1 & 410.7 & 0.00233 & - & 411 & 597 & 282 & \\
\hline & Sigmoid & 107 & 249.42 & 3 & 0.012 & 227.9 & 339 & 340 & & & \\
\hline \multirow{4}{*}{ Haor beel } & Schaefer & 40 & 90.76 & 4 & 1.105 & -0.00050 & - & 612 & & & 1108 \\
\hline & Fox & 40 & 85.48 & 2 & 0.331 & -0.00117 & - & 439 & & & 856 \\
\hline & Asymptotic & 40 & 83.49 & 1 & 391.1 & 0.00424 & - & 391 & 700 & 259 & \\
\hline & Sigmoid & 40 & 87.48 & 3 & 0.023 & 109.4 & 313 & 313 & & & \\
\hline \multirow[t]{4}{*}{ Open beel } & Schaefer & 76 & 196.42 & 2 & 1.666 & 0.00065 & - & 1069 & & & 1283 \\
\hline & Fox & 76 & 196.43 & 3 & 0.526 & -0.00051 & - & 1230 & & & 1976 \\
\hline & Asymptotic & 76 & 196.43 & 3 & 1516.8 & 0.00112 & - & 1517 & & & \\
\hline & Sigmoid & 76 & 195.71 & 1 & 0.013 & 213.1 & 774 & 774 & 1435 & 458 & \\
\hline \multirow[t]{4}{*}{ River } & Schaefer & 116 & 310.86 & 4 & 0.797 & 0.00006 & - & 2522 & & & 6327 \\
\hline & Fox & 116 & 292.32 & 3 & -0.076 & -0.00030 & - & 1142 & & & 3351 \\
\hline & Asymptotic & 116 & 269.72 & 2 & 478.7 & 0.00266 & - & 479 & & & \\
\hline & Sigmoid & 116 & 264.12 & 1 & 0.00191 & 891.9 & 690.2 & 690 & 1800 & 427 & \\
\hline
\end{tabular}


Table 4. Combined negative log likelihoods and Akaike weights for each model

\begin{tabular}{llllll}
\hline Model & $\sum_{h} L L_{m, h}$ & $\boldsymbol{p}$ & $\boldsymbol{A I C}_{\boldsymbol{m}, \text { combined }}$ & $\boldsymbol{\Delta}_{\boldsymbol{m}}$ & $\boldsymbol{W}_{\boldsymbol{m}}$ \\
\hline Schaefer & 446.18 & 2 & 896.35 & 67.56 & 0.00 \\
Fox & 428.05 & 2 & 860.11 & 31.31 & 0.00 \\
Asymptotic & 412.40 & 2 & 828.79 & 0.00 & 0.85 \\
Sigmoid & 413.10 & 3 & 832.20 & 3.41 & 0.15 \\
\hline
\end{tabular}
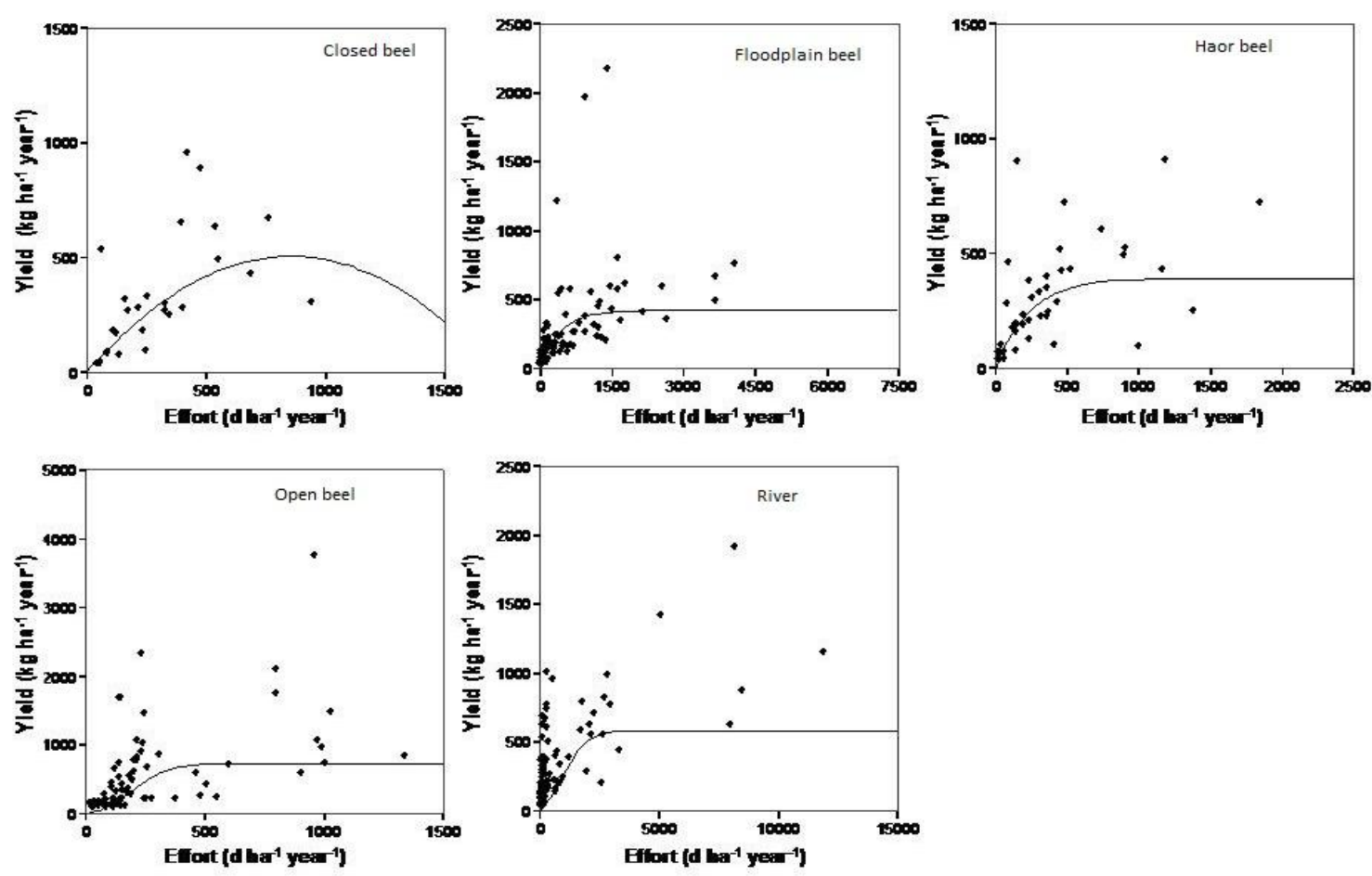

Fig. 1. Aggregated yield vs. fishing effort for left to right and top to bottom: Closed beel, floodplain beel, haor beel, open beel and river habitat with most likely models

Table 5. Estimates of yield, effort and remaining biomass proportion for an $E_{0.1}$ and an $E_{0.2}$ strategy for the fisheries examined

\begin{tabular}{llllllll}
\hline & Parameter & $\begin{array}{l}\text { Closed } \\
\text { beel }\end{array}$ & $\begin{array}{l}\text { Floodplain } \\
\text { beel }\end{array}$ & Haorbeel & $\begin{array}{l}\text { Open } \\
\text { beel }\end{array}$ & River & $\begin{array}{l}\text { Habitat } \\
\text { average }\end{array}$ \\
\hline$E_{0.1}$ & $Y_{E_{0.1}}\left(\mathrm{~kg} \mathrm{ha}^{-1} \mathrm{year}^{-1}\right)$ & 796 & 370 & 352 & 1365 & 431 & 663 \\
& $E_{0.1}\left(\mathrm{~d} \mathrm{ha}^{-1} \mathrm{year}^{-1}\right)$ & 1761 & 998 & 545 & 2052 & 867 & 1245 \\
& $C P U E_{E_{0.1}}\left(\mathrm{~kg} \mathrm{~d}^{-1}\right)$ & 0.45 & 0.37 & 0.65 & 0.67 & 0.50 & 0.53 \\
& $C P U E_{\max }\left(\mathrm{kg} \mathrm{d}^{-1}\right)$ & 1.16 & 0.95 & 1.65 & 1.70 & 1.27 & 1.34 \\
& $C P U E_{E_{0.1}} / C P U E_{\max }$ & 0.39 & 0.39 & 0.39 & 0.39 & 0.39 & 0.39 \\
$E_{0.2}$ & $Y_{E_{0.2}}\left(\mathrm{~kg} \mathrm{ha}^{-1} \mathrm{year}^{-1}\right)$ & 708 & 330 & 313 & 1214 & 383 & 590 \\
& $E_{0.2}\left(\mathrm{~d} \mathrm{ha}^{-1} \mathrm{year}^{-1}\right)$ & 1231 & 691 & 381 & 1435 & 606 & 869 \\
& $C P U E_{E_{0.2}}\left(\mathrm{~kg} \mathrm{~d}^{-1}\right)$ & 0.58 & 0.48 & 0.82 & 0.85 & 0.63 & 0.67 \\
& $C P U E_{\max }\left(\mathrm{kg} \mathrm{d}^{-1}\right)$ & 1.16 & 0.95 & 1.65 & 1.70 & 1.27 & 1.34 \\
& $C P U E_{E_{0.1}} / C P U E_{\max }$ & 0.50 & 0.50 & 0.50 & 0.50 & 0.50 & 0.50 \\
\hline
\end{tabular}




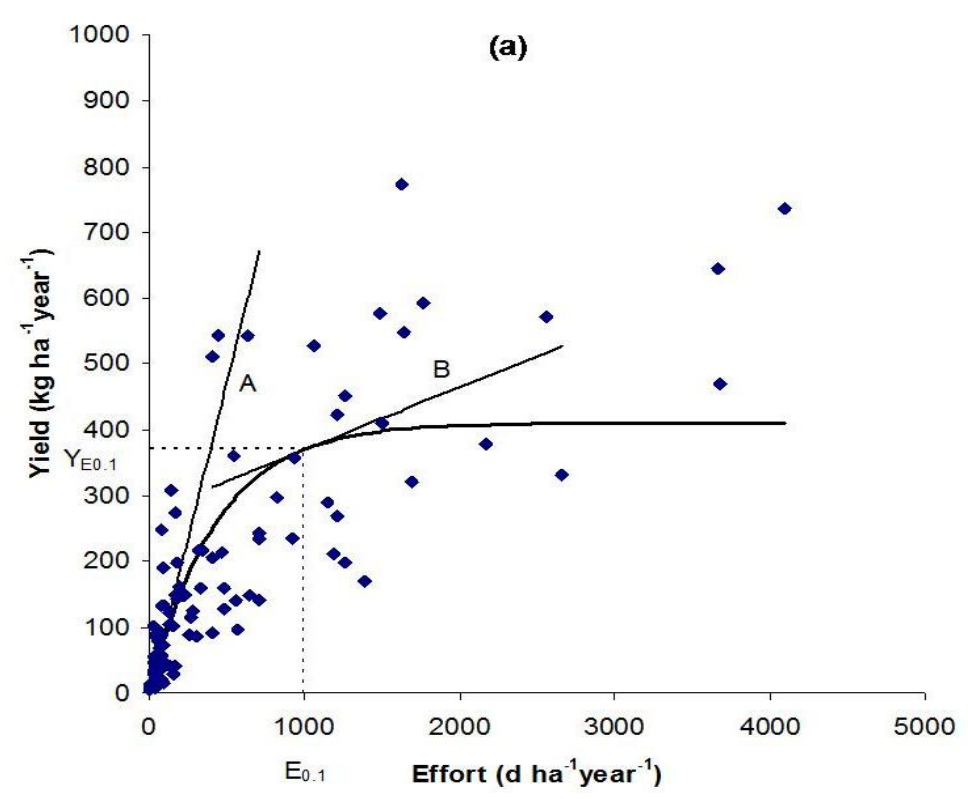

Fig. 2. (a) The asymptotic model fitted to the data for floodplain beel fisheries. Line A-slope of curve at origin, Line B-10\% of slope of curve at the origin. $E_{0.1}$ and $Y_{E_{0.1}}$ are the effort and yield estimates respectively corresponding to the point on the curve where its slope is $10 \%$ of that at the origin

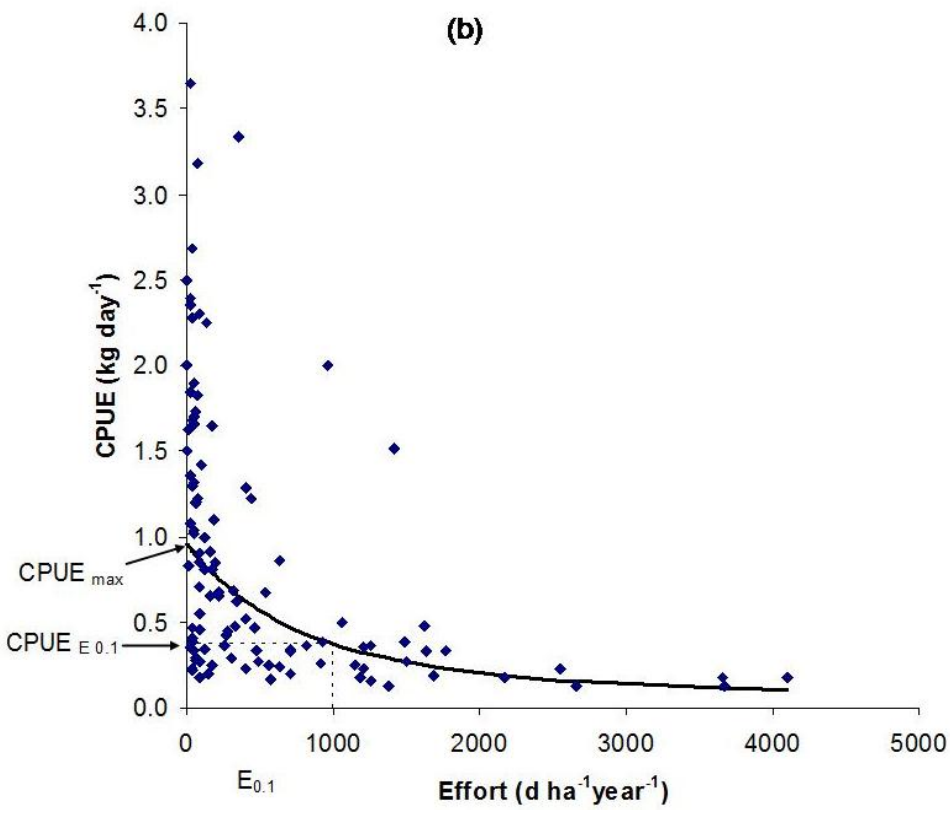

Fig. 2. (b). Corresponding plot illustrating the response of CPUE to effort. The $x$-axis has been truncated for the purposes of the illustration omitting three outliers

If the asymptotic model is indeed a generally applicable description of the aggregated yieldeffort response for small-scale inland fisheries of Bangladesh, then alternative reference target or limit reference points to those developed for the
Schaefer and Fox type models which exhibit a maximum yield at some intermediate level of effort (e.g. maximum yield, MY and effort corresponding to maximum yield, $E_{\mathrm{MY}}$ ) will need to be formulated. 
A potential candidate reference point for the asymptotic model might be an effort-based analogue of the ad hoc ' $F_{0.1}$ strategy' employed for yield-per-recruit analysis [9]. Here we define $E_{0.1}$ as the effort where the slope of the yieldeffort response is 0.1 times the initial slope. Fig. 2a illustrates an $E_{0.1}$ strategy for the floodplain beel fisheries examined here. For these fisheries, $E_{0.1}$ corresponds to an effort of $998 \mathrm{~d} \mathrm{ha}^{-1}$ year $^{-1}$ for a predicted yield of $370 \mathrm{~kg}$ ha $^{-1}$ year $^{-1}$.

The slope of the yield-effort curve at the origin provides an approximate estimate of the predicted maximum CPUE $\left(C P U E_{\text {max }}\right)$. If it is assumed that the catchability coefficient, $q$ remains constant with changing effort, then in our example, the biomass of the floodplain beel fish community at $E_{0.1}\left(C P U E_{E_{0.1}}\right)$ will have been reduced to approximately $40 \%$ ( $C P U E_{E_{0.1}} / C P U E_{\max }=0.39$ ) of its approximate predicted maximum (Fig. 2b) where

$$
\operatorname{CPUE} E_{E_{0.1}}=\frac{Y_{E_{0.1}}}{E_{0.1}}
$$

The proportion of remaining biomass $\left(C P U E_{E_{0.1}} / C P U E_{\max }\right)$ at $E_{0.1}$ ranges between approximately 0.39 and 0.41 (approximately $40 \%$ ) over a wide range of values for $b$. This compares with a 50\% remaining biomass predicted at $E_{\mathrm{MY}}$ for a Schaefer model response. In our example, a more conservative limit reference point such as $E_{0.2}$, which gives a $C P U E_{E_{0.2}} / C P U E_{\max }$ value of between 0.49 and 0.51 (approximately $50 \%$ ) over a wide range of values for $b$, may therefore be preferred.

Catch rates (CPUE) might be easily monitored to determine progress towards the reference point $\left(C P U E_{E_{0 . x}}\right)$. A summary of the two alternative strategies for the fisheries examined here is given in Table 5. As a general 'rule of thumb' for any habitat, catch per fisher, averaged over the year, should not be allowed to fall below approximately $0.5 \mathrm{~kg} \mathrm{~d}^{-1}$ or $0.7 \mathrm{~kg} \mathrm{~d}^{-1}$ for the more conservative reference point.

This proposed $E_{0 . x}$ reference point may provide a useful management reference point for fisheries other than those operating in Bangladesh or exploiting other aquatic habitats where the aggregated yield-effort response is asymptotic.
Besides effort, other management controls designed to improve or optimize yield-per-recruit might be considered. The process of formulating relevant management strategies would be considerably more challenging if the sigmoid model was more generally applicable because of the highly non-linear response of CPUE to effort. At moderate levels of effort, reductions in effort may give rise to a decline in CPUE. Determining the exploitation status of the fishery may therefore be necessary to predict the effect of changes to fishing effort on CPUE. Because of such non-linear features, [10] also urge "extreme caution when interpreting aggregated CPUE as an indicator of fishing impacts on the exploited community".

The CBFM Project was largely ineffective in controlling overall fishing effort and gear use. However, the implementation of closed seasons during the rising flood, designed to increase the length or age of fish at first capture, had a significant effect on CPUE [7]. Other management strategies for fisheries exhibiting an asymptotic response of catch to effort to meet a range of alternative socio-economic and conservation objectives have been proposed [16].

\section{CONCLUSION}

Both the asymptotic and the sigmoid model each provided the best description of the yield-effort response within two habitats. The Schaefer model provided the best description of the data for closed beel habitat. However, among all habitats, the Akaike weight favoured the asymptotic over the sigmoid model while the Schaefer and Fox were the least favoured models. The study has provided evidence that across habitat favoured an asymptotic yield-effort model (Akaike weight 0.85 ) as being the most generally applicable. However, further research appears warranted to confirm the generality of the aggregated catch-effort response.

\section{ACKNOWLEDGEMENTS}

The authors are grateful to Robin Welcomme, Kai Lorenzen, Malcolm Dickson and Alan Brooks for their comments, advice and support during the preparation of the manuscript. Thanks also to Mohammod Ilyas, Khalilur Rahman, Susmita Choudhury and Ismat Ara (WorldFish) for their valuable contributions towards the compilation, analysis and interpretation of the data. This research and dissemination was funded by the 
Department for International Development (DfID). The views expressed are not necessarily those of DfID.

\section{COMPETING INTERESTS}

Authors have declared that no competing interests exist.

\section{REFERENCES}

1. DoF. National fish week 2016 compendium. Department of Fisheries, Ministry of Fisheries and Livestock, Bangladesh; 2016.

2. Mustafa MG, Firoz Khan AKM, Mohsin SkM. Community-based resources management approaches adopted in the three tributaries of river Surma, North-East Bangladesh. J. Fish. Aquat. Sci. 2017;12:54-63.

3. Firoz Khan AKM, Mustafa MG, Niamul NM. Effective supervision of inland capture fisheries of Bangladesh and its hurdles in managing the resources. Bandung $\mathrm{J}$ of Global South. 2016;3(17):1-12.

4. Naser MN. Fish conservation efforts in Bangladesh: How to make it more effective. In Proc. Of The Festschrift on the $50^{\text {th }}$ Anniversary of the IUCN Red List of Threatened Species. IUCN Bangladesh; 2014.

5. Halls AS, Mustafa G, Malcolm D. An empirical bio-economic stocking model for floodplain beels in Bangladesh. Aquaculture Research. 2007;38:947-952.

6. Halls AS, Welcomme RL, Burn RW. The relationship between multispecies catch and effort: Among fishery comparisons. Fisheries Research. 2006;77:78-83.

7. Mustafa MG, Halls AS. Impact of the community based fisheries management on sustainable use of inland fisheries in Bangladesh. CBFM-2 International Conference on Community-Based Approaches to Fisheries Management, WorldFish, Bangladesh; 2007.

8. Ralston S, Polovina JJ. A multispecies analysis of the commercial deep-sea handline fishery in Hawaii. Fishery Bulletin. 1982;80:435-448.

9. Hilborn R, Walters CJ. Quantitative fisheries stock assessment: Choice, dynamics and uncertainty. New York, Chapman Hall; 1992.

10. Lorenzen $\mathrm{K}$, Almeida $\mathrm{O}$, Arthur $\mathrm{R}$, Garaway C, Nguyen-Khoa S. Aggregated yield and fishing effort in multispecies fisheries: An empirical analysis. Canadian Journal of Fisheries and Aquatic Science. 2006;63:1334-1343.

11. Sparre $P$, Venema SC. Introduction to tropical fish stock assessment. FAO Fisheries Technical Paper 306; 1992.

12. Schaefer MB. Fishery dynamics and present status of the yellowfin tuna population of the eastern Pacific Ocean. Bull. I-ATCC/Bol. CIAT. 1967;12(3):89136.

13. Fox WW. An exponential surplus yield model for optimising exploited fish populations. Transactions of the American Fisheries Society. 1970;99:80-88.

14. Laë R. Does overfishing lead to a decrease in catches and yields? An example of two West African coastal lagoons. Fisheries Management and Ecology. 1997;3:101-116.

15. Haddon M. Modelling and quantitative methods in fisheries. London, Chapman Hall; 2001.

16. Welcomme RL. Inland fisheries: Conservation and management. Oxford, Blackwell; 2001.

(c) 2017 Halls and Mustafa; This is an Open Access article distributed under the terms of the Creative Commons Attribution License (http://creativecommons.org/licenses/by/4.0), which permits unrestricted use, distribution, and reproduction in any medium, provided the original work is properly cited.

Peer-review history:

The peer review history for this paper can be accessed here: http://sciencedomain.org/review-history/19594 